\title{
Isolated plexiform neurofibroma mimicking a vascular lesion*
}

\author{
Paola Cecilia Stefano ${ }^{1}$ \\ Agustina Maria Lanoë ${ }^{1}$ \\ Sergio Sierre ${ }^{1}$
}

\author{
Sebastian Nicolas Apa ${ }^{1}$ \\ Josefina Sala María ${ }^{1}$ \\ Adrián Martin Pierini ${ }^{1}$
}

DOI: http:/ / dx.doi.org/10.1590/abd1806-4841.20164300

\begin{abstract}
Plexiform neurofibromas are benign tumors originating from peripheral nerve sheaths, generally associated with Neurofibromatosis Type 1 (NF1). They are diffuse, painful and sometimes locally invasive, generating cosmetic problems. This report discusses an adolescent patient who presented with an isolated, giant plexiform neurofibroma on her leg that was confused with a vascular lesion due to its clinical aspects. Once the diagnosis was confirmed by surgical biopsy, excision of the lesion was performed with improvement of the symptoms.
\end{abstract}

Keywords: Adolescent; Leg; Neurofibroma, plexiform

A 13-year-old, female patient was referred to our Dermatology Department with a congenital lesion on the posterior part of her leg that had progressively increased in size. The dermatological examination revealed a soft tumor throughout the posterior part of her right leg, with a violet erythema overlying macula, angioma-like feature and pigmented circular areas of approximately $1 \mathrm{~cm}$ in diameter (Figure 1 ). Nodular lesions in this lesion were tender at touch. They were not adherent to the skin but looked adherent in extremely painful depth. The patient also had a café-aulait spot on her chest. Other tumors and nodules were not palpated in the rest of the tegument. A magnetic resonance imaging (MRI) was performed with and without gadolinium. Subsequently, a large poliovoid mass was observed close beneath the subcutaneous cellular tissue. It extended among the femoral bicep fibers and semimembranous of the right thigh, with a posterolateral external flow area in the leg of up to $7 \mathrm{~cm}$ above the calcaneal. The image was hypointense on T1, and hyperintense on T2, with low endovenous contrast enhancement on IR, informed as an extensive, venous, vascular malformation (Figure 2).
Suspecting thrombosis due to a venous malformation, we requested a phlebology test, which revealed a permeable superficial and deep venous system without malformations.

A surgical biopsy was performed for a histopathological study (Figure 3), revealing a fusiform cell proliferation appearing in nodules with stretched and pale eosinophilic cytoplasm (Figures 4 and 5). The nodules showed thin fascicles, which were compactly ordered in some areas and more laxly in others, over myxoid stroma. Furthermore, they were delimited by a capsule of fibrous tissue, with diffuse dermal and hypodermal involvement. There was no sign of pleomorphism, mitotic figures or necrosis.

The patient had no family background of Neurofibromatosis Type 1, which was ruled out after complementary tests with normal outcomes.

Following a diagnosis of isolated plexiform neurofibroma, the lesion was resectioned and the patient is currently undergoing follow-up treatment to assess the relapse.

\footnotetext{
Received on 14.12.2014

Approved by the Advisory Board and accepted for publication on 01.07.2015

Work performed at the National Hospital of Pediatrics "Prof. Dr. Juan P. Garrahan" - Buenos Aires, Argentina.

Financial Support: None.

Conflict of Interest: None.

1 National Hospital of Pediatrics "Prof. Dr. Juan P. Garrahan" - Buenos Aires, Argentina.
}

(C2016 by Anais Brasileiros de Dermatologia 


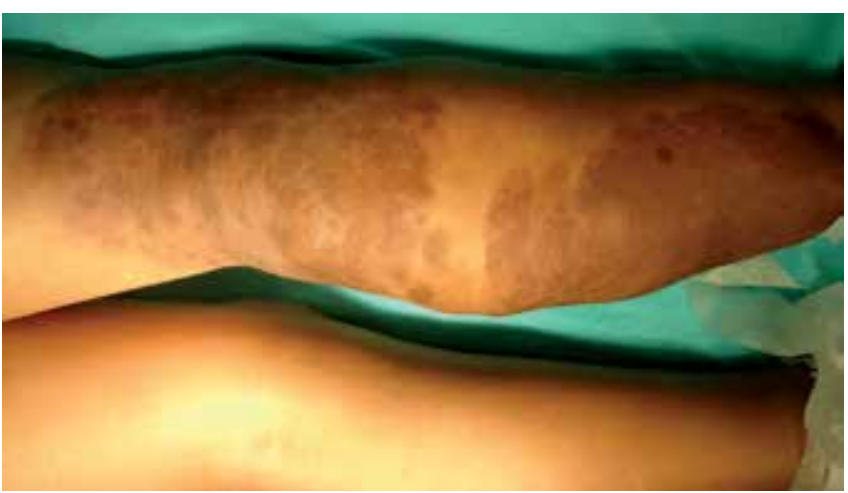

FiguRE 1: Tumor with hyperpigmented and circular areas

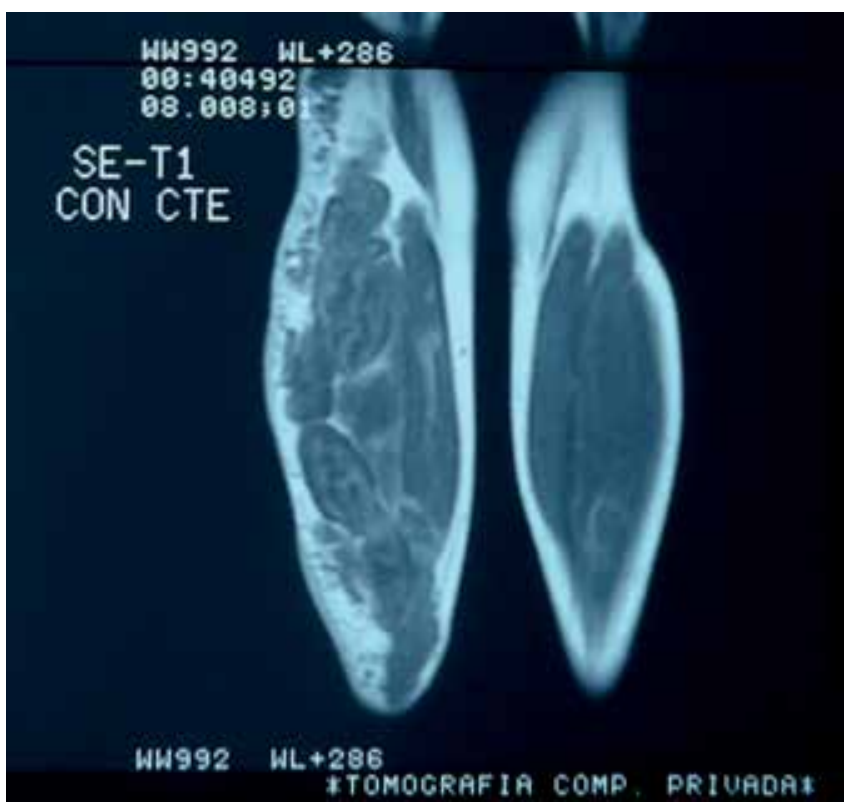

FIGURE 2: Conglomerate mass in the MRI, hypointense on T1 and low endovenous contrast enhancement

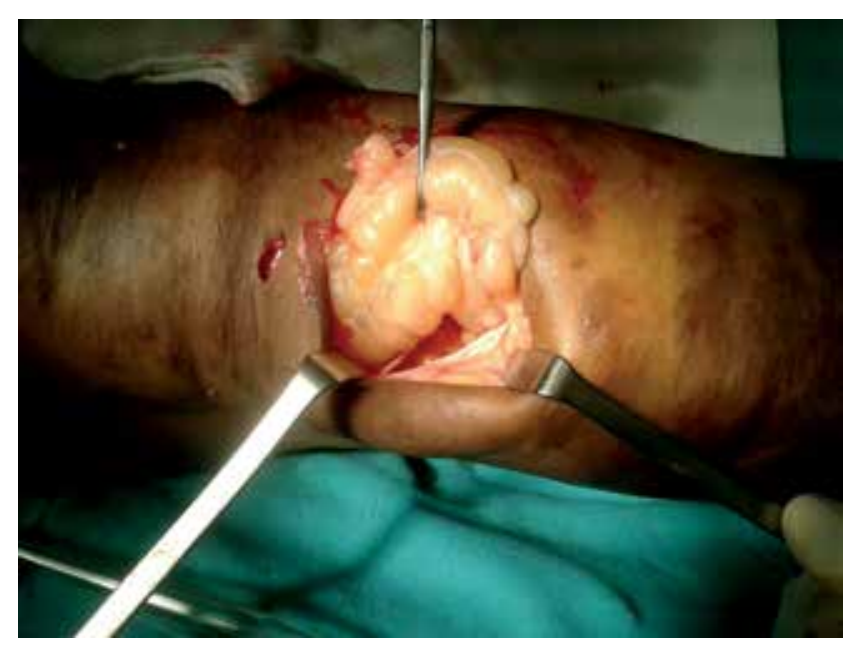

FIGURE 3: Intraoperative image

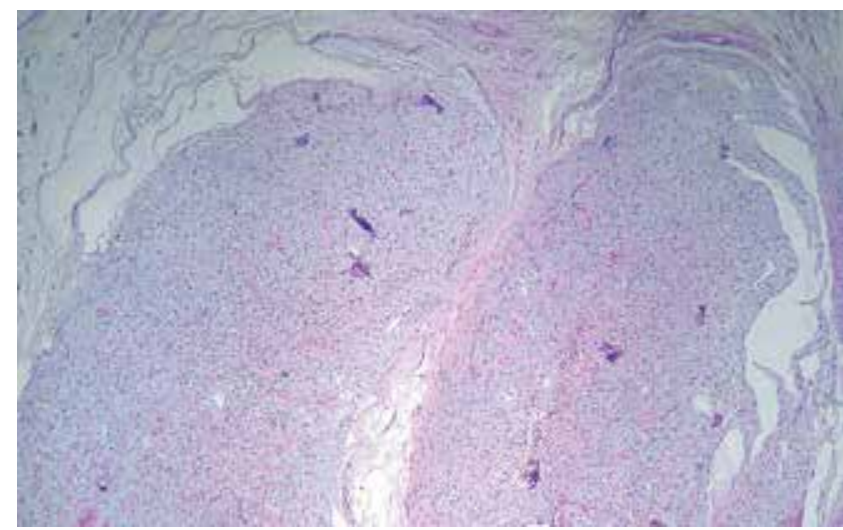

Figure 4: $\mathrm{H}$ and E 40x. Fusiform cell proliferation disposed into nodules

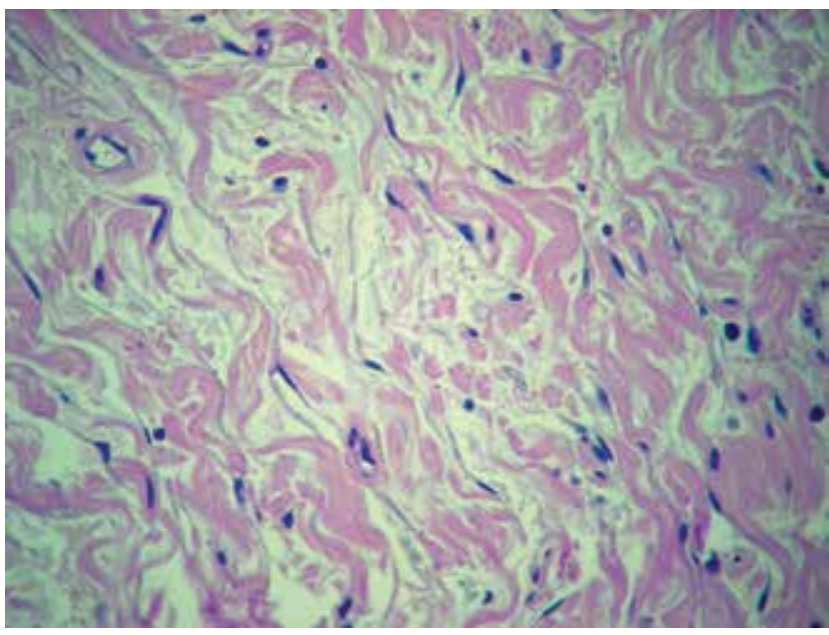

Figure 5: $\mathrm{H}$ and E 400x. Fusiform cell proliferation. Nuclei in italic $S$

\section{DISCUSSION}

Plexiform neurofibroma is an uncommon tumor originating in peripheral nerve sheaths and histologically constituted by Schwann cell proliferation, organized in myxoid stroma. It is probably congenital, appearing at the ages of 4 or 5 , while deep lesions can manifest in adulthood. ${ }^{1}$

A third of patients with diagnosis of Neurofibromatosis Type 1 have the condition, although it has also been described as an isolated entity. It is frequently located on the head and neck due to the rich innervations of the area; however, they have also been described in the extremities, where they follow the axis of a nervous track, appearing in a cord-like form. ${ }^{2-3}$ Plexiform neurofibromas are generally large, infiltrative tumors, without defined borders. They entail pigmented, overlying skin with an angiomatous aspect; hypertrichosis may also be located in the lesion, producing a nevoid aspect. ${ }^{1}$ Two main features stand out: hyperextensibility with a lack of elasticity, and palpation that mimics a bag of worms. Plexiform neurofi- 
bromas can be nodular or diffused; the diffused form is known as elephantiasis neurofibromatosa. They are often painful to palpation and can be present at birth, but often appear between the ages of 2 and 5 . Thus far, most published cases of plexiform neurofibroma have involved adults, affecting mainly the mouth. However, other reports have described the condition in the orbit, hand, bladder, vulva, back, along with two cases in the leg (as in the present case): one involving a 5-year-old girl, the other an 8-year-old boy. ${ }^{4-5}$ The risk of malignant transformation into neurofibrosarcoma is between 2 and $5 \%$, which should be suspected if the initial lesion grows quickly and significantly. Imaging studies are rarely specific - although MRI is character- istic - and classically have peripheral nerve tumors, with low to moderate T1 signal, hyperintense on T2 with heterogeneous aspect. The areas with the highest signals correspond to those of myxoid tissue or cystic degeneration. Nodular areas of low signal correspond to collagenous and fibrous tissue, and might have been enhanced with gadolinium. ${ }^{5}$

In many cases, surgical excision is complicated since it may involve the main nervous branches. Relapse after resection depends on the possibility of total or partial resection, which is related to tumoral infiltration. ${ }^{6}$ There have been reports of children without relapses at 2 and 4 years of follow-up.

\section{REFERENCES}

1. Tsao H., Luo S. Neurofibromatosis and Tuberous Sclerosis. In: Bolognia JL, Jorizzo JL, Schaffer JV, editors. Dermatology. 3th ed. Oxford: Elsevier; 2012: 61 , 925-941.

2. Levy Bencheton A, Mallet S, Rojat Habib MC, Figarella-Branger D, Sigaudy S, Grob JJ, et al. Isolated late-onset plexiform neurofibroma in the absence of neurofibromatosis. Ann Dermatol Venereol. 2010;137:301-4.

3. Marocchio LS, Oliveira DT, Pereira MC, Soares CT, Fleury RN. Sporadic and multiple neurofibromas in the head and neck region: a retrospective study of 33 years. Clin Oral Investig. 2007;11:165-9.

4. Cebesoy 0, Tutar E, Isik M, Arpacioglu 0. A case of isolated giant plexiform neurofibroma involving all branches of the common peroneal nerve. Arch Orthop Trauma Surg. 2007;127:709-12.

5. Lange F, Herlin C, Frison L, Bessis D, Rouleau-Dubois C, Bigorre M, et al. Management of plexiform neurofibroma isolated in childhood: About four observations. Ann Chir Plast Esthet. 2013:58:694-9.

6. Fujiwara M, Isaka F, Honjo G, Ozawa T, Tachibana T. Solitary plexiform neurofibroma: recurrence 32 years after excision. J Eur Acad Dermatol Venereol. 2006;20:756-7.
MAILING ADDRESS:

Paola Cecilia Stefano

Pichincha 1881

1249 - Capital Federal - Argentina

E-mail: paoladermatologia@yahoo.com.ar

How to cite this article: Stefano PC, Apa SN, Lanoël AM, Josefina SM, Sergio S, Martín PA. Isolated plexiform neurofibroma mimicking a vascular lesion. An Bras Dermatol. 2016;91(2):240-2. 